\begin{tabular}{||l|l|}
\hline Citation & $\begin{array}{l}\text { Maesschalck, Jeroen (2021), Using grid-group cultural theory to assess } \\
\text { approaches to the prevention of corporate and occupational crime: the EU as } \\
\text { natural experiment. In: N. Lord, E. Inzelt, W. Huisman, R. Faria, European white } \\
\text { collar crime. Exploring the nature of European realities. Bristol University Press. }\end{array}$ \\
\hline Archived version & $\begin{array}{l}\text { Author manuscript: the content is identical to the content of the published } \\
\text { paper, but without the final typesetting by the publisher }\end{array}$ \\
\hline Author affiliation & $\begin{array}{l}\text { Jeroen Maesschalck, Leuven Institute of Criminology, Faculty of Law, KU } \\
\text { Leuven (University of Leuven), Belgium }\end{array}$ \\
\hline Author contact & Jeroen.Maesschalck@kuleuven.be \\
\hline 32 (0) 16 325588
\end{tabular}




\section{Using grid-group cultural theory to assess approaches to the prevention of corporate and occupational crime: the EU as natural experiment}

Jeroen Maesschalck, Leuven Institute of Criminology, KU Leuven

\section{Acknowledgement}

The author wishes to thank the participants in the seminar of the European Working Group on Organizational Crime (EUROC) in Manchester in June 2019 and particularly the discussants Judith Van Erp and Aleksandra Jordanoska for their suggestions. He also thanks Rita Faria, Nick Lord, Milou Van Dijk and Marco Verweij for their very helpful comments on a later draft of the paper. 
"We have traveled little distance in the project of mutual learning from differences that discriminate and similarities that converge toward a more general social science of deterrence, persuasion, self-regulation, enforced self-regulation, and reintegration."

(Braithwaite, 2016, p. 15)

\section{Introduction}

In the 2015 volume on white-collar and corporate crime in Europe, Lord and Levi (2015) argue that much work remains to be done if we want to really understand white-collar crime prevention. We not only need to understand more about the phenomenon of white-collar crime itself, e.g. by combining quantitative data with qualitative information (Lord \& Levi, 2015), but also about the efforts to prevent it. This implies that researchers should move beyond "crude indicators of levels of enforcement" such as prosecution data (Lord \& Levi, 2015, p. 41) and look at descriptors of a broad range of types of regulation of which criminal prosecution is just one. It is to that latter research agenda, using mixed methods research to understand white-collar crime prevention, that this paper intends to contribute.

Specifically, the paper will propose a number of building blocks for a theoretical framework to address the question 'what works in the prevention of corporate and occupational crime?' and it will argue that Europe provides a promising environment to test and further develop such a framework. An important advantage of the European and particularly the EU context, is that a number of relevant environmental characteristics (e.g. EU law and policies) are shared, while there is still important and theoretically useful variation across countries, industries and organizations.

These reflections will be formulated in three steps. First, the paper will present a number of classifications to map variation in corporate and occupational crime prevention approaches in Europe. After the presentation of a classification used within ethics management at organizational level and a classification used within regulation at industry level, it will argue for a more generic classification drawn from grid-group cultural theory. Second, against the background of those classifications, the paper will identify the building blocks of a theoretical framework that could guide research on the impact of efforts to prevent corporate and occupational crime. Third, some designs for empirical research within the EU to test and further develop the proposed theoretical framework will be briefly discussed.

\section{Mapping variation in the prevention of corporate and occupational crime}

Before addressing approaches to prevention, it is useful to first delineate what it is that is to be prevented. This is a common challenge in the field of white collar-crime research, notorious for its conceptual and terminological debates. Essentially, this paper focuses on a particular category of white-collar crime: crime within and by organizations. There is no generic term to describe this phenomenon. Most authors refer to it by using two labels (Clinard \& Quinney, 1973; Coleman, 1987, p. 407; Gerber \& Jensen, 2007, pp. xiii-xiv; Huisman, 2016). The first label, occupational crime, then refers to crimes committed by employees for their own benefit. The second label, corporate (or, more generally, organizational) crime, refers to crimes committed by employees or organizations for the benefit of the organization. The distinction between both is not always clear-cut, as crime is sometimes committed both for individual and organizational benefit (Gerber \& Jensen, 2007, p. xiv), nor is it really important 
for this paper. That is why this paper will refer to 'corporate and occupational crime', 'crime within and by organizations' or sometimes the more generic label 'white-collar crime'.

Research in various academic fields generated assorted classifications and typologies to conceptualize variation in approaches to the prevention of corporate and occupational crime. The growing field of regulation is an obvious source of classifications and we will indeed draw from it. However, as Almond and van Erp (2018) observe, most studies in the field of regulation largely overlook individual-level motivations and mechanisms within the regulated organization. That is why, we would argue, insights from the literature on regulation can be usefully complemented with insights from organizational ethics and particularly ethics management. Starting from the lower level of analysis, this paragraph will first present a classification from organizational ethics and then discuss a number of classifications from research on regulation. It will conclude with a third, more generic classification that helps to encompass the previous classifications.

The first classification of white-collar crime prevention approaches focuses on the organizational level. As Huisman (2016) describes, an important strand within the white-collar crime research tradition focuses on the organization itself as criminogenic. This has delivered very useful explanations of crime within organizations, but it does not really offer typologies of strategies for its prevention. For that, it is useful to turn to the growing field of business ethics or organizational ethics and to look at the prevention of crime within organizations as an aspect of "ethics management". The most classic distinction of approaches in this field is between the rules-based (or compliance-based) and values-based approaches to ethics management (Paine, 1994). The rules-based approach emphasizes extensive formal controls that reduce individual employees' discretion (e.g. rules, monitoring and powerful enforcement). The values-based approach, on the other hand, accepts employees' discretion and offers support for using that discretion (e.g. frequent deliberation about ethical dilemmas, coaching, aspirational codes of ethics) (e.g. Cooper, 2006; Maesschalck, 2004a; Paine, 1994).

The second classification, or rather group of classifications, focuses on prevention at a higher level: the approaches that can be used by regulators to prevent crime by and within the organizations they regulate. The classifications of those approaches are remarkably similar to those used within organizations in the ethics management literature. Gunningham (2010, 2016), for example, distinguishes between the 'rules and deterrence' approach and the 'advice and persuasion' approach'1. The former emphasizes the sanctioning of rule breaking behavior and expects that sufficiently frequent detection and sufficiently severe punishment will deter from future violations. The latter emphasizes cooperation over confrontation, using bargaining and negotiation instead of deterrence (Gunningham, 2010, pp. 121-122).

\footnotetext{
${ }^{1}$ The literature on regulation often refers to the latter strategy as 'compliance' (e.g. Gunningham, 2010, p. 121), thus referring to voluntary compliance, as opposed to enforced compliance as a consequence of deterrence. Likewise, referring to debates in the 1980s and 1990s on how to react to while collar crime, Lord and Levi (2015, p. 40) also refer to the 'compliance' and 'deterrence' approaches. Interestingly and confusingly, the ethics management literature at organizational level often uses 'compliance' as a label for what we described as the 'rules-based' approach (e.g. Paine, 1994), thus referring to the fact that employees are expected to comply with rules and regulations rather than to use ethical decision making in which those rules are just one source. Thus, while there are significant similarities between the dichotomies in both areas, the label 'compliance' is used in opposite sides of the dichotomy.
} 
The third classification is more ambitious as it claims to be more comprehensive and generic. It is inspired by grid-group cultural theory (also called the theory of 'sociocultural viability' (Thompson, Ellis, \& Wildavsky, 1990)), which was originally developed by the anthropologist Mary Douglas (1970) and later applied at various levels of analysis (international and national regulatory regimes, organizational policies) and in various academic fields relevant to the study of white-collar crime, including criminology (Mars, 2006; Vaughan, 2002; Vaughan, 2004), regulation (Lodge \& Hood, 2010) and organizational ethics (Maesschalck, 2004a). Table 1 below draws from Maesschalck (2004a) and Lodge and Hood (2010, p. 599) to present the four approaches to the prevention of corporate and occupational crime that can be derived from grid-group cultural theory. The typology is defined by two dimensions. 'Grid' refers to the extent to which life is circumscribed by externally imposed conventions and rules, and 'group' refers to the extent to which individuals are bound in a collective unit (Hood, 1998, p. 8; Thompson et al., 1990, p. 5). Together, they define four approaches to corporate and occupational crime prevention that can be presented in a 2 by 2 matrix.

Table 1: four approaches to corporate and occupational crime prevention

\begin{tabular}{|c|c|c|c|}
\hline \multicolumn{4}{|c|}{ Group } \\
\hline & & Low & High \\
\hline & High & $\begin{array}{l}\text { Fatalism and contrived randomness } \\
\text { Ensure a considerable degree of } \\
\text { randomness and unpredictability in } \\
\text { the standard setting as well as the } \\
\text { interactions. }\end{array}$ & $\begin{array}{l}\text { Hierarchy and oversight } \\
\text { Provide rules and regulations (usually } \\
\text { on the basis of expert advice) and } \\
\text { enforce these strictly. }\end{array}$ \\
\hline 음 & Low & $\begin{array}{l}\text { Individualism and rivalry } \\
\text { Ensure as much competition as } \\
\text { possible so as to avoid e.g. unethical } \\
\text { monopoly rents or nepotism at } \\
\text { organizational level or excessive } \\
\text { power concentration, shirking or } \\
\text { unhealthy loyalties at the level of } \\
\text { individual employees. }\end{array}$ & $\begin{array}{l}\text { Egalitarianism and mutuality } \\
\text { Allow organizations or individuals a } \\
\text { considerable degree of discretion and } \\
\text { support them in dealing with it. If } \\
\text { there are any rules and standards, } \\
\text { they are set through a participatory } \\
\text { process and applied by persuasion. }\end{array}$ \\
\hline
\end{tabular}

The two high-group types at the right-hand side of the matrix are very close to the distinctions in the previous two typologies. The hierarchy and oversight approach is very close to the rulesbased approach to ethics management and to the deterrence approach to regulation. The egalitarianism and mutuality approach largely coincides with the values-based approach to ethics management and the advice and persuasion approach to regulation. The two remaining low-group approaches on the left-hand side of the table feature much less in typologies of ethics management or regulation, but can nevertheless be found in the practice of corporate and occupational crime prevention. Rivalry and competition have become popular approaches to regulation. In the wake of the success of the 'new public management' rhetoric, they are 
seen as ways to avoid corruptly charged monopoly trends (Klitgaard, 1988). They have also been suggested as solutions to avoid occupational crime within organizations. In the public sector, for example, pay-for-performance schemes and other forms of competition among employees were introduced to reduce the risk of shirking. Competition among (senior) employees is also expected to ensure that they keep each other honest. It might help to avoid dangerous concentration of power within individual employees as well as to avoid unhealthy loyalties that might lead to cover-ups (Hood, 1998, pp. 55-60). Likewise, the unpredictability typical for fatalism and contrived randomness can also been found in both regulation and ethics management within organizations. Surprise inspections, for example, are a common feature of most regulatory regimes. Contrived randomness is also common within organizations, e.g. in the form of random internal audits or unpredictable posting of employees to avoid "over-familiarity with clients or colleagues" (Hood, 1998, p. 65). In sum, this typology is more generic than the typologies in regulation and ethics management and as a fourfold typology it is broader than the two-way distinctions in regulation and ethics management. It is also embedded in a much broader literature, which allows to link the four different approaches presented here with different worldviews (including different views on risk (e.g. Sparks, 2001)) and different ways of organizing. That broader grid-group typology has been used, for example, to describe and compare national cultures (e.g. Caulkins, 1999; Hood, James, Peters, \& Scott, 2004; Maleki \& Hendriks, 2015), making it particularly useful for the aim of this paper.

\section{Understanding what works in the prevention of corporate and occupational crime}

\section{Combining approaches}

Having distinguished between different approaches to corporate and occupational crime prevention, the obvious next question is what their respective impact is: to what extent do they 'work'? The conclusion for all three classifications in the previous paragraph seems to be largely the same: all the respective approaches have their advantages but also their disadvantages and, in practice, it will often be some kind of mix of several approaches that will be most effective. We briefly develop this argument for each of the three classifications.

First, each of the two approaches to ethics management has its own dark side ${ }^{2}$. If an organization only went for the rules-based approach, then this might weaken moral competence (and particularly moral imagination) of its staff, undermine employee morale, generate increasingly complex layers of rules and exceptions, lead to fear-induced paralysis, etc. However, if an organization allowed the values-based approach to develop unabatedly, this might lead to indecisiveness because of endless discussions, individual employees abusing their discretion, etc. Thus, each of the separate approaches will generate its own excesses if the approach is allowed to grow relentlessly. To avoid that, organizations should ensure a sufficient degree of each of the approaches, which would allow those approaches to compensate for each other's weaknesses and blind spots. Thus, the rule-fetishism and rigidity of the rules-based approach will be alleviated by the discretion and strengthened moral imagination that follow from the values-based approach. Likewise, cunning employees' abuse

\footnotetext{
2 This paragraph is almost entirely taken from Maesschalck (2019).
} 
of a naïve form of the values-based approach can be prevented by having at least a minimum of the rules, monitoring and enforcement that are typical for the rules-based approach. Thus, the recommendation is to ensure some kind of balance between the two approaches. In that sense they are rather to be seen as extremes on a continuum, with real organizations usually taking a position somewhere in-between (Maesschalck, 2004a).

Second, a very similar argument can be found in the regulation literature. Gunningham also describes 'rules and deterrence' and 'advice and persuasion' as "two polar extremes" (Gunningham, 2010, p. 122) and observes that most regulatory specialists now recommend a judicious mix of both approaches (Gunningham, 2010, p. 125). Focusing on the individual enforcement officer, May and Winter (2011, p. 229) describe punitive or strict enforcement on the one hand and an accommodative or conciliatory regulatory style on the other as the ends of a continuum with more moderate, adaptive styles in the middle. Probably the best known representation of the various approaches to regulation is the enforcement pyramid, proposed by Ayres and Braithwaite (1992) as part of their broader theory on 'responsive regulation'. At the bottom, the pyramid presents the most cooperative strategies (guidance, persuasion) and at the top the most deterrent one (nondiscretionary punishment, incapacitation) (Ayres \& Braithwaite, 1992, pp. 35-40). With this pyramid comes a sophisticated theory about how the approaches relate to each other. At the core of this theory is a strong normative recommendation that regulators should only escalate towards deterrence and then incapacitation when repeat interaction showed that the regulated actor is not able and/or willing to comply (Braithwaite, 2011, pp. 30-34). More recent models have further expanded these ideas by taking on board the complexities of polycentric regulatory regimes in which regulation occurs through a web of not only state actors but also private and third sector actors at regional, national and transnational level. Proponents of "smart regulation", for example, argue that in many cases the use of multiple regulatory instruments and a broad range of actors will be most effective (Gunningham, 2010, p. 131; Gunningham, Grabosky, \& Sinclair, 1998). In fact, as Almond and van Erp (2018, p. 10) observe, "the interaction between deterrence and compliance, and the ways in which state sanctions and social pressures reinforced each other's effectiveness" was "a defining feature of the emergent research of the 1990s and 2000s at the intersection of corporate criminology and regulatory governance".

The regulation literature also has its own versions of the argument that we also saw in the ethics management literature: complementary approaches can compensate for their respective weaknesses. For example, in explaining responsive regulation, Braithwaite observes that the different theories underlying the various approaches that are represented in the layers of the regulatory pyramid "are all limited and flawed theories of compliance". Hence "[w]hat the pyramid does is cover the weakness of one theory with the strength of another" (Braithwaite, 2002, p. 32). If escalation to deterrence and eventually incapacitation is a real threat, then it is rational for regulated actors to comply even without any coercion being exercised (Braithwaite, 2011, p. 475). Gunningham offers another reason why the advice and persuasion approach is not sufficient. If that approach leads the regulator to allow wrongdoers to go unpunished, then this might discourage well-intended organizations from complying, as their investment in compliance would lead to a competitive disadvantage (Gunningham, 2010, p. 125). Hence, if the advice and persuasion approach is to be effective, it has to do so "in the shadow of deterrence" (Gunningham, 2016, p. 515). Finally, Lord and 
Levi $(2015$, p. 41) formulate a similar argument in the area of corporate crime by describing a 'spectrum of regulatory mechanisms'. At one end would be various levels of self-regulation within industries and organizations and at the other end would be various enforcement practices (e.g. criminal prosecution, disruption strategies, licensing mechanisms) that are mainly performed by state actors. As such, the lines between regulation and criminal procedure become increasingly blurred. Again, the argument is that contradictory approaches can reinforce each other, for example when regulatory techniques enable prosecution (Lord \& Levi, 2015, p. 41).

Third, it is again grid-group cultural theory that offers the most ambitious approach. Because it hypothesizes a fourfold typology defined by two dimensions instead of a continuum defined by a single dimension, it allows for more complex and nuanced thinking. It does not look for a middle position between the extremes of a continuum, nor does it propose a normative argument about the escalation of approaches along one dimension (as is done with the regulatory pyramid). Instead, it allows for a more complex dynamic between the four types along two dimensions. For example, while the traditional continua in ethics management suggest that, say, less hierarchy (i.e. rules-based approach) implies more egalitarianism (i.e. values-based approach), the fourfold typology allows to see that less hierarchy might also lead to two other outcomes: more individualism or even more fatalism (Maesschalck, 2004a). This is a very important addition that might help to avoid blind spots. As with the discussed continua in ethics management and regulation, grid-group cultural theory predicts that each of the approaches has its own built-in weaknesses that will inevitably occur if the approach is not compensated for by the other three approaches. This basic insight is developed into a theory that predicts that, particularly for wicked problems such as white-collar crime, 'clumsy' or 'polyrational' policies that combine elements of all four types will be more viable (Ney \& Verweij, 2015; Verweij et al., 2006). That theory has generated a series of studies in various policy fields further testing and developing this basic idea (Lodge, 2009; Verweij \& Thompson, 2006). In sum, grid group cultural theory not only helps to bring together typologies commonly used in the ethics management and the regulation literatures in one typology, it also generates hypotheses about the expected impact of the types. Applied to the topic, this would imply that those countries, industries or organizations that do not offer a corporate and occupational crime prevention policy that is sufficiently diverse across the four types, will exhibit more corporate and occupational crime than others.

\section{Looking for the 'right' combination}

The prediction that crime prevention approaches will be more effective when they are sufficiently diverse is just the start of a theory, of course. It certainly does not mean that all policies that combine elements of various approaches will be desirable. Simply piling up instruments and approaches will not do. Braithwaite, Makkai, and Braithwaite (2007, p. 312), warn against a 'kitchen sink' approach to regulation, referring to Gunningham et al. (1998)'s warning against 'smorgasbordism', i.e. "wrongly assuming that all complementary instruments should be used rather than the minimum number necessary to achieve the desired result" (Gunningham \& Sinclair, 2017, p. 134). One would hope, though, that some combinations are more fruitful than others and that a theory would help us understand why that is the case. I now propose three roads towards developing a more sophisticated theory. 
The first road is the most developed one in the ethics management and the regulation literatures. It is a contingency approach, focusing on conditions: depending on the circumstances, the appropriate mix between the approaches (or the position on the continuum) will differ. The typologies and continua used in the regulation literature often come with specifications of the conditions under which particular types should be used. Responsive regulation's regulatory pyramid, for example, prescribes that regulators adapt their strategy to the compliance motives they ascribe to those they regulate (Mascini, 2016). In a further development of the regulatory pyramid, Braithwaite et al. (2007, pp. 305-323) propose to adapt the regulatory strategy to levels of complexity. Risk based-regulation expects regulators to adapt their strategy to the risks that non-compliance by the regulated might pose to their mission (Black \& Baldwin, 2010, p. 181; Mascini, 2016). Similar arguments, specifying which approach (or rather combination of approaches) should be used under which circumstances exist in the ethics management literature (e.g. Maesschalck, 2004a).

The second road resembles the first one, but it particularly focuses on the different ways in which the approaches can be combined, the types of 'settlements' between the contradictory approaches. It theorizes different ways of combining approaches and hypothesizes what the likely impact of such combinations will be under various circumstances. Thacher and Rein (2004), for example, show that balancing values or striking trade-offs between values is just one strategy of dealing with contradictory approaches (and hence values). They propose three alternative ways of managing conflict between values (and, we would add, hence also between grid-group cultural theory's four perspectives). The first alternative approach they propose is to cycle between values by first emphasizing one value and then the other. A case in point is the pendulum dynamic that can be seen in ethics management in organizations between the rules-based and values-based approaches, with scandals often playing a role in changing the direction of the pendulum. In responsive regulation, this sequence is deliberately designed. It prescribes that regulators should escalate or de-escalate on the pyramid depending on the degree of cooperation by the regulated actor "so that, in sequence, the strengths of one tool be given a chance to cover the weaknesses of another tool" (Braithwaite, 2011 , p. 505). The second alternative to balancing proposed by Thacher and Rein (2004) is to organize a structural separation between values by assigning the responsibility for those values to different institutional actors. In ethics management, these could take the form of 'firewalls' within organizations, e.g. separating the investigative unit on the one hand from an ethics unit that provides support and training on the other. An example of structural separation in a regulatory context is provided by Braithwaite (2002, p. 35)'s restorative justice approach to responsive regulation (as opposed to the "tit for that" approach to responsive regulation (Nielsen \& Parker, 2009)). This restorative justice approach prescribes that individual regulatory staff members always focus on cooperation and take a positive attitude towards the regulated actor. They never have to sanction or even threaten to sanction. This is possible because there are other actors in a broader system of escalating sanctions for noncompliance who will take up the punitive role if necessary (Nielsen \& Parker, 2009, pp. 395396). As such, the structural separation between cooperation on the one hand and punitive actions on the other helps to combine both contradictory approaches in a functioning overall system. The third alternative to balancing values proposed by Thacher and Rain (2004) is that of 'casuistry': trying to transcend value conflicts from case to case, relying on one's experience with previous cases. Both the ethics management and regulatory literature offer examples of this gradual, pragmatic approach. In conclusion, Thacher and Rein (2004) argue that, 
depending on the context, all four approaches to manage value conflict (balancing, cycling, structural separation, casuistry) could be 'rational' and they offer some hypotheses about the conditions under which each approach is most promising. Others have built on Thacher and Rein's work by using empirical research to add more approaches to managing value conflicts (e.g. de Graaf, Huberts, \& Smulders, 2014; Stewart, 2006). This road could generate hypotheses about the impact of particular combinations of approaches to the prevention of corporate and occupational crime. Such hypotheses would be more sophisticated than the simple hypotheses about the impact of one approach that were formulated above, but they would also be less complicated and more parsimonious than a virtually endless list of hypotheses about the impact of all imaginable combinations between approaches.

A third road to further develop the idea of combining approaches is suggested by the gridgroup cultural theory literature itself. This road particularly focuses on the dynamics between the approaches to understand their impact. Drawing from social systems theory, 6 (2003) proposes two mechanisms to explain those dynamics: positive and negative feedback. Positive feedback is a process by which an approach reinforces itself through a dynamic of selfradicalization. This can be benign at the start, but as the ethics management and regulation literatures described above would predict, at some stage it will become vicious and selfdestructive. Negative feedback occurs when the approaches clash. This could be the correcting 'homeostatic' processes described above where, for example, the values-based approach to ethics management is checked by the rules-based approach. Yet, not all negative feedback leads to these correcting dynamics. Sometimes, the negative feedback can lead to gridlock or extreme forms of polarization. Using these two fundamental forces, Perri 6 (2003) proposes a theory on 'institutional viability', distinguishing between different forms of settlements between the four types of grid-group cultural theory.

Conclusion: what works for whom in what circumstances and how?

Inspired by realist evaluation (Pawson \& Tilley, 1997), our original 'what works in corporate and occupational crime prevention?' question can be reformulated in the more nuanced 'what works for whom in what circumstances?' This section attempted to offer the building blocks for a theoretical framework that guides the answer to this question.

First, and most obviously, as for the 'what' in 'what works', we argued that the grid-group typology provides a language that can be used to conceptualize a broad range of corporate and occupational crime prevention approaches. It claims that the effectiveness of a specific crime prevention strategy in a specific regulatory regime or organization will depend on an appropriate mix between the four grid-group types. A hypothetical example in the area of ethics management can help to make this more concrete: the prevention of theft by employees. A policy that emphasizes the two high-grid quadrants in Table 1 comes easily to mind. Such a policy would combine elements of the hierarchist type, such as clear rules that include well-defined procedures for sanctioning those who break those rules, with some fatalist elements such as random inspections or unpredictable staffing. While less obvious, the low-grid quadrants of Table 1 could also generate interesting ideas. From an egalitarian perspective, an employee theft prevention policy would emphasize fair treatment of staff members, relying on a long tradition of research showing the impact of fairness on unethical behaviour such as stealing (e.g. Greenberg, 1990). It would also emphasize group loyalty and 
solidarity within the organization, expecting that this would reduce the likelihood that people want to damage the organization through stealing. An individualist employee theft prevention policy could contain incentive schemes. These might reward individuals who report on stealing by their colleagues or might offer free products to members of units where no stealing has been reported. More generally, one might expect that an individualist, entrepreneurial culture with fair rewards for performance might reduce the temptation to steal. Grid-group cultural theory would predict that each of these approaches not only has its desirable effects, but also its built-in risks and excesses. For example, if allowed to develop unabated, hierarchy and fatalism can lead to a rigid, rule-obsessed attitude among staff that weakens creativity and innovation. They can also demotivate staff and provoke reactance, thus ironically increasing the risk of employee theft. Their emphasis on respecting authority can also lead to staff members not speaking out against stealing managers. Of course, egalitarianism also carries its risks. Strong ties among employees increases the risk of collusion to steal. Likewise, individualism's emphasis on self-interest and individual performance can lead to a 'greed is good' culture that actually increases the risk of stealing. With all four types having their advantages as well as disadvantages, it is important to develop an appropriate mix that allows the types to compensate for each other's excesses. For example, an egalitarian-style emphasis on group solidarity and an individualist emphasis on entrepreneurial attitude might help to compensate for the suffocating rigidity and paranoia that might come from fatalism. Egalitarianism can also help to mitigate the risks of an individualist-style emphasis on performance. Egalitarianism's own risk of unhealthy loyalties can in turn be mitigated by a mix of individualism, unpredictability (and hence fatalism) and clear rules and sanctions (and hence hierarchy). This employee theft example helps to show the power of the framework in developing the 'what' in 'what works'. It supports creativity in the design of prevention strategies by offering four perspectives, it recognizes that each of the four perspectives has its own risks and it proposes to prevent those risk by designing an appropriate mix of the four perspectives.

Second, the 'works for whom', part in our central research question might be the most contested one. ${ }^{3}$ There are many different stakeholders in corporate and occupational crime prevention who all might have their own view on what it means for crime prevention to work. From a regulatory perspective, one might argue that the real indicator for success in, say, environmental crime prevention is less pollution (Braithwaite, 2016). Hence, if a conciliatory approach would reduce pollution it would be considered successful, even if that would mean perpetrators from the past getting away unpunished. Those reflecting from a more critical corporate crime perspective, on the other hand, might emphasize the importance of the punishment itself. From this perspective, criminalization is about satisfying public demands for justice, and more conciliatory approaches might undermine that goal (Almond \& van Erp, 2018 , p. 8). The fourfold grid-group typology might offer a fresh way of looking at these debates. Underlying each of the four approaches is a worldview that generates different views of risks and hence different definitions of what is to be counted as success. Earlier work by Vaughan $(2002 ; 2004)$ to use the typology to describe various approaches to punishment and social control might be helpful here.

\footnotetext{
${ }^{3}$ While in realist evaluation research 'works for whom' usually refers to the differential impact of an intervention on different groups of people, it might also refer to different perspectives on the intervention.
} 
Third, as for the 'in what circumstances' part of the central research question, the contingency approaches to ethics management and regulation provide many conditions that might help to explain the success or failure of particular approaches to the prevention of corporate and occupational crime. The grid-group typology might help to reduce the complexity of those factors. For that, it might look for inspiration in earlier studies that used grid-group cultural theory to describe national cultures in the European Union (Grendstad, 1999; Mamadouh, 1999) or across the world (Akbar \& Vujić, 2014), bearing mind that using 'national culture' to explain corporate and occupational crime is not without its problems (Jou, Hebenton, \& Chang, 2016). The typology has also been used to describe organizational culture (Maesschalck, 2004b; Wouters \& Maesschalck, 2014), an important contextual factor for crime prevention within organizations.

Europe as a laboratory to test what works in the prevention of corporate and occupational crime

This section proposes some ideas for a research agenda to test and further develop in a European context the theoretical framework of which some building blocks were presented above. Before turning to some examples of research designs, it is useful to point out that strategies to prevent corporate and occupational crime could work at different levels of analysis: teams or units within an organization, organizations, networks of organizations, industries, cities, regions, countries, and the various transnational levels. Research designs could focus on all these levels separately, but could also aim to combine multiple levels, as will often be necessary to really understand corporate and occupational crime and how it can be prevented. Punch (2008, pp. 108-111)'s account of Nick Leeson's fraudulent behavior that led to the collapse of the Barings bank is a useful illustration. It shows failures in the Singapore office where he was working, in the bank's head office in London, at the level of the regulators and at the level of the banking industry as a whole.

The three research designs proposed here are intended to address the basic research question introduced above: what works in corporate and occupational crime prevention? Against the background of the discussion above, that very general question can be specified in many more specific research questions. Some examples can illustrate this: Is the grid-group typology of four approaches to corporate and occupational crime prevention empirically meaningful and analytically useful? Does empirical research show that a mix of the four types is more effective than strategies that are less polyrational? Are some combinations more effective than others in a particular context? If so, what are those combinations (e.g. using Thacher and Rein (2004)'s classification) and which elements in the context make a difference? Do mechanisms like positive and negative feedback help to explain the evolution of prevention strategies and their impact over time?

A first possible design to address those questions, would consist of multiple case studies to assess the impact of a particular prevention strategy, i.e. a particular mix of approaches in a particular context. To do that kind of analysis one would hope to find cases that are largely similar in context, but different in their prevention strategy. That would allow for conclusions where variation in the outcome can be explained by variation in the prevention strategies. To some extent, the EU provides such an environment. Member states share the EU's overall legal and regulatory framework and, to varying degrees, some characteristics of their political 
and cultural environment. At the same time, countries or even regions still differ significantly in their specific mix of approaches to the prevention of corporate and occupational crime. One could, for example, compare different prevention strategies in different countries within the same industry. A particularly interesting design would be to investigate a multinational company operating in several European countries and to compare how the same company responds to different prevention approaches within an overall shared framework and market. This is not to say, of course, that the EU provides a perfect natural experiment. There will be variations in the context (e.g. national political culture, related policies) and differences in crime prevention approaches will be confounded with those variations. In practice, it will be difficult to know whether differences in outcomes should be ascribed to the crime prevention approach, to those contextual factors or to an interaction between both. While the experimental logic might help in the sampling of the cases (only vary on the intervention and keep the context as constant as possible), the actual research would benefit more from other, more flexible approaches such as realist evaluation (Pawson, 2006; Pawson \& Tilley, 1997). The latter takes variation in context as a given and focuses on how, in a particular context, the intervention (e.g. a particular corporate and occupational crime prevention strategy) triggers particular mechanisms that lead to a particular outcome.

A second interesting design to address the research questions listed above, would be case studies centered around time series. In a critique of a systematic review on corporate crime deterrence (Schell-Busey, Simpson, Rorie, \& Alper, 2016), Braithwaite (2016) argues for such designs. He particularly invites criminologists to focus on big changes over time. Those changes can be beneficial, such as with the dramatic reduction in fatalities in mining in the UK and France in the $20^{\text {th }}$ century, but they can also be problematic as with indicators of growing crime in the pharmaceutical industry (Braithwaite, 2016). While such studies would start from a quantitative time series, they should become real case studies, combining all types of quantitative and qualitative data to develop an explanation for those evolutions (Braithwaite, 2016). It would be very interesting to develop such time series for a particular phenomenon (e.g. types of environmental pollution, types of crime in pharmaceutical industry) for several European countries. Comparative case studies would then investigate whether changes in the corporate and occupational crime prevention policy (and particularly positive and negative feedback dynamics between the approaches and the resulting mixes of approaches) help to explain between-country variations in the time series.

Third, cross-sectional quantitative studies could also help to test the theoretical framework introduced above in An EU context. At organizational level, standardized measurement instruments could be developed to map the specific prevention strategies (as a combination of the four approaches) used within these organizations. This would then allow to see whether those strategies and the way they are combined correlate with incidence of corporate and occupational crime or other, related indicators. Similar studies could be imagined to compare national approaches in a particular industry across countries. Mixed methods designs are also possible, of course. One could, for example, apply nested analysis (Lieberman, 2005; Swedlow, Kall, Zhou, Hammitt, \& Wiener, 2009) by using the results of cross-sectional large-N research as a basis for the sampling of more in-depth case studies.

None of these designs will be easy to develop and many issues will have to be addressed. Some of those are specific to the theoretical framework. For example, how is it possible to 
measure a mixture of four approaches in a systematic way? Others are well-known in the study of white-collar crime.

\section{Conclusion}

In her afterword to the 2015 volume on white-collar and corporate crime in Europe, Croall (2015) concludes:

"Even if asking a 'what works question' is hampered by measurement and evidential difficulties, exploring alternative forms of law, different levels of state and selfregulation, compliance policies and different forms of sanction through comparative work and case studies is of great importance." (Croall, 2015, p. 544)

While acknowledging these many difficulties, this paper nevertheless attempted to address the 'what works' question by proposing the building blocks of a theoretical framework and suggesting three research designs to further test and develop that theoretical framework in a European context.

The advantage of reducing research on the prevention of corporate and occupational crime to an answer to the 'what works?' question, is that it provides focus. In doing so, it increases the chance of cumulative research that progressively generates more sophisticated insights that are actually useful for practice. The disadvantage of such a focus, and particularly the focus on 'what works?', is the risk of developing blind spots, particularly for normative issues behind the question. To some extent, the suggestions formulated in this paper do address those normative concerns. Expanding 'what works?' to 'what works for whom in what circumstances?' takes on board an awareness of the many different interests and perspectives that are at play in the prevention of corporate and occupational crime. Likewise, the proposed fourfold typology not only presents four approaches to the prevention of corporate and occupational crime, it also refers to four more fundamental worldviews. Hence, the recommendation that real-life prevention strategies should combine elements of all four approaches is actually also an argument for ideological pluralism. Sufficient sensitivity to these normative issues will remain important, however. The ambiguity that will result from polyrational combinations of all four types can also have its own price. Nelken (2012), for example, shows the risks of moral ambiguity around corporate crime and how this could lead to more permissive environments. 
6, P. (2003). Institutional viability: a neo-Durkheimian theory. Innovation: the European journal of social science research, 16(4), 395-416.

Akbar, Y., \& Vujić, V. (2014). Explaining corruption: The role of national culture and its implications for international management. Cross Cultural Management, 21(2), 191-218. doi:10.1108/CCM03-2013-0050

Almond, P., \& van Erp, J. (2018). Regulation and governance versus criminology: disciplinary divides, intersections, and opportunities. Regulation \& Governance. doi:10.1111/rego.12202

Ayres, I., \& Braithwaite, J. (1992). Responsive regulation: transcending the deregulation debate. Oxford: Oxford University Press.

Black, J., \& Baldwin, R. (2010). Really responsive risk-based regulation. Law \& Policy, 32(2), 181-213.

Braithwaite, J. (2002). Restorative justice and responsive regulation. Oxford: Oxford University Press.

Braithwaite, J. (2011). The essence of responsive regulation. University of British Columbia Law Review, $44,475-520$.

Braithwaite, J. (2016). In Search of Donald Campbell. Criminology \& Public Policy, 15(2), 417-437. doi:10.1111/1745-9133.12198

Braithwaite, J., Makkai, T., \& Braithwaite, V. A. (2007). Regulating aged care: ritualism and the new pyramid. Cheltenham: Edward Elgar Publishing.

Caulkins, D. D. (1999). Is Mary Douglas's grid/group analysis useful for cross-cultural research? CrossCultural Research, 33(1), 108-128.

Clinard, M. B., \& Quinney, R. (1973). Criminal behavior systems. A typology. 2nd ed. New York: Holt, Rinehart and Winston.

Coleman, J. W. (1987). Toward an integrated theory of white-collar crime. The American Journal of Sociology, 93(2), 406-439.

Cooper, T. (2006). The responsible administrator: an approach to ethics for the administrative role. 5th ed. San Fransisco: Jossey-Bass.

Croall, H. (2015). White collar crime in Europe: afterword. In J. van Erp, W. Huisman, \& G. Vande Walle (Eds.), The Routledge handbook of white-collar and corporate crime in Europe (pp. 533-547). Oxon: Routledge.

de Graaf, G., Huberts, L., \& Smulders, R. (2014). Coping with public value conflicts. Administration \& Society, 48(9), 1101-1127. doi:10.1177/0095399714532273

Douglas, M. (1970). Natural symbols: explorations in cosmology. New York: Random House.

Gerber, J., \& Jensen, E. L. (Eds.). (2007). Encyclopedia of white-collar crime. Westport, Connecticut: Greenwood Press.

Greenberg, J. (1990). Employee theft as a reaction to underpayment inequity: The hidden cost of pay cuts. Journal of Applied Psychology, 75(5), 561-568.

Grendstad, G. (1999). A political cultural map of Europe. A survey approach. GeoJournal, 47, 463-475.

Gunningham, N. (2010). Enforcement and compliance strategies. In R. Baldwin, M. Cave, \& M. Lodge (Eds.), The Oxford handbook of regulation (pp. 120-145). Oxford: Oxford University Press.

Gunningham, N. (2016). Regulation: From Traditional to Cooperative. In S. R. Van Slyke, M. L. Benson, \& F. T. Cullen (Eds.), The Oxford handbook of white-collar crime (pp. 503-520). Oxford: Oxford University Press.

Gunningham, N., Grabosky, P., \& Sinclair, D. (1998). Smart regulation: designing environmental policy. Oxford: Oxford University Press.

Gunningham, N., \& Sinclair, D. (2017). Smart regulation. In P. Drahos (Ed.), Regulatory theory: Foundations and applications (pp. 133-148). Acton: Australian National University Press.

Hood, C. (1998). The art of the state. Culture, rhetoric, and public management. Oxford: Clarendon Press.

Hood, C., James, O., Peters, G. B., \& Scott, C. (2004). Controlling modern government. Variety, commonality and change. Cheltenham: Edward Elgar Press. 
Huisman, W. (2016). Criminogenic organizational properties and dynamics. In S. R. Van Slyke, M. L. Benson, \& F. T. Cullen (Eds.), The Oxford handbook of white-collar crime (pp. 435-462). Oxford: Oxford University Press.

Jou, S., Hebenton, B., \& Chang, L. (2016). Cultural variation. In S. R. Van Slyke, M. L. Benson, \& F. T. Cullen (Eds.), The Oxford handbook of white-collar crime (pp. 345-366). Oxford: Oxford University Press.

Klitgaard, R. (1988). Controlling corruption. Los Angeles: University of California Press.

Lieberman, E. S. (2005). Nested analysis as a mixed-method strategy for comparative research. American political science review, 99(3), 435-452.

Lodge, M. (2009). The public management of risk: the case for deliberating among worldviews. Review of Policy Research, 26(4), 395-408. doi:10.1111/j.1541-1338.2009.00391.x

Lodge, M., \& Hood, C. (2010). Regulation inside government: retro-theory vindicated or outdated? In R. Baldwin, M. Cave, \& M. Lodge (Eds.), The Oxford handbook of regulation (pp. 590-609). Oxford: Oxford University Press.

Lord, N., \& Levi, M. (2015). Determining the adequate enforcement of white-collar and corporate crimes in Europe. In J. van Erp, W. Huisman, \& G. Vande Walle (Eds.), The Routledge handbook of white-collar and corporate crime in Europe (pp. 39-56). Oxon: Routledge.

Maesschalck, J. (2004a). Approaches to ethics management in the public sector. A proposed extension of the compliance-integrity continuum. Public Integrity, 7(1), 21-41. doi:10.1080/10999922.2004.11051267

Maesschalck, J. (2004b). Research note: a method for applying cultural theory in the study of organizations. Innovation: the European Journal of Social Sciences, 17(4), 377-386.

Maesschalck, J. (2019). Facing the dark side: on the unintended, unanticipated and unwelcome consequence of ethics management. In C. L. Jurkiewicz (Ed.), Global corruption and ethics management: translating theory into action (pp. 159-166). New York: Roman \& Littlefield Publishers.

Maleki, A., \& Hendriks, F. (2015). Grid, group, and grade: challenges in operationalizing cultural theory for cross-national research. Cross-Cultural Research, 49(3), 250-280. doi:10.1177/1069397114555843

Mamadouh, V. (1999). National political cultures in the European Union. In M. Thompson, G. Grendstad, \& P. Selle (Eds.), Cultural theory as political science (pp. 138-153). London: Routledge.

Mars, G. (2006). Changes in occupational deviance: Scams, fiddles and sabotage in the twenty-first century. Crime, Law and Social Change, 45, 285-296.

Mascini, P. (2016). Comparing assumptions underlying regulatory inspection strategies: implications for oversight policy. In S. R. Van Slyke, M. L. Benson, \& F. T. Cullen (Eds.), The Oxford handbook of white-collar crime (pp. 521-539). Oxford: Oxford University Press.

May, P. J., \& Winter, S. C. (2011). Regulatory enforcement styles and compliance. In C. Parker \& V. L. Nielsen (Eds.), Explaining compliance: Business responses to regulation (pp. 222-244). Cheltenham: Edward Elgar.

Nelken, D. (2012). White-collar and corporate crime. In M. Maguire, R. Morgan, \& R. Reiner (Eds.), The Oxford Handbook of Criminology. Fifth edition. (pp. 623-659). Oxford: Oxford University Press.

Ney, S., \& Verweij, M. (2015). Messy institutions for wicked problems: How to generate clumsy solutions? Environment and Planning C: Government and Policy, 33(6), 1679-1696.

Nielsen, V. L., \& Parker, C. (2009). Testing responsive regulation in regulatory enforcement. Regulation \& Governance, 3(4), 376-399.

Paine, L. S. (1994). Managing for organizational integrity. Harvard Business Review, 72(2), 106-117.

Pawson, R. (2006). Evidence-based policy. A realist perspective. London: Sage.

Pawson, R., \& Tilley, N. (1997). Realistic evaluation. London: Sage.

Punch, M. (2008). The organization did it: Individuals, corporations and crime. In J. Minkes \& L. Minkes (Eds.), Corporate and white-collar crime (pp. 102-121). London: Sage. 
Schell-Busey, N., Simpson, S. S., Rorie, M., \& Alper, M. (2016). What works? A systematic review of corporate crime deterrence. Criminology \& Public Policy, 15(2), 387-416. doi:10.1111/17459133.12195

Sparks, R. (2001). Degrees of estrangement: the cultural theory of risk and comparative penology. Theoretical Criminology, 5(2), 159-176. doi:10.1177/1362480601005002002

Stewart, J. (2006). Value conflict and policy change. Review of Policy Research, 23(1), 183-195. doi:10.1111/j.1541-1338.2006.00192.x

Swedlow, B., Kall, D., Zhou, Z., Hammitt, J. K., \& Wiener, J. B. (2009). Theorizing and generalizing about risk assessment and regulation through comparative nested analysis of representative cases. Law \& Policy, 31(2), 236-269.

Thacher, D., \& Rein, M. (2004). Managing value conflict in public policy. Governance, 17(4), 457-486. doi:10.1111/j.0952-1895.2004.00254.x

Thompson, M., Ellis, R., \& Wildavsky, A. (1990). Cultural theory. Boulder: Westview Press.

Vaughan, B. (2002). Cultured punishments: the promise of grid-group theory. Theoretical Criminology, 6(4), 411-431.

Vaughan, B. (2004). The greening and governance of crime control. Criminal Justice, 4(1), 5-28. doi:10.1177/1466802504042221

Verweij, M., Douglas, M., Ellis, R., Engel, C., Hendriks, F., Lohmann, S., ... Thompson, M. (2006). Clumsy solutions for a complex world: The case of climate change. Public Administration, 84(4), 817843.

Verweij, M., \& Thompson, M. (2006). Clumsy solutions for a complex world: governance, politics and plural perceptions. Houndmills: Palgrave Macmillan.

Wouters, K., \& Maesschalck, J. (2014). Surveying organizational culture to explore grid-group cultural theory: instrument design and preliminary empirical results. International Journal of Organizational Analysis, 22(2), 224-246. 